\title{
Oncological outcome after lung metastasis in patients presenting with localized chondrosarcoma at extremities:Tokai Musculoskeletal Oncology Consortium study
}

\author{
This article was published in the following Dove Press journal: \\ OncoTargets and Therapy \\ 29 July 2016 \\ Number of times this article has been viewed
}

\begin{abstract}
Tomoki Nakamura, ' Akihiko
Matsumine,' Satoshi

Yamada, ${ }^{2}$ Satoshi Tsukushi, ${ }^{3,4}$

Katsuhisa Kawanami, ${ }^{5}$

Takatoshi Ohno, ${ }^{6}$ Hirohisa

Katagiri, ${ }^{7}$ Hideshi Sugiura, ${ }^{3,8}$

Kenji Yamada, ${ }^{9}$ Yoshihisa

Yamada, ${ }^{10}$ Akihiro Sudo,

Yoshihiro Nishida ${ }^{4}$

'Department of Orthopaedic Surgery, Mie Graduate School of Medicine, TsuCity, Mie, ${ }^{2}$ Department of Orthopedic Surgery, Graduate School of Medical Sciences, Nagoya City University, ${ }^{3}$ Department of Orthopedic Surgery, Aichi Cancer Center Hospital, ${ }^{4}$ Department of Orthopaedic

Surgery, Nagoya University Graduate School of Medicine, Nagoya, Aichi, ${ }^{5}$ Department of Orthopaedic Surgery, Aichi Medical University School of Medicine, Nagakute, ${ }^{6}$ Department of Orthopaedic Surgery, Gifu University Graduate School of Medicine, Gifu, ${ }^{7}$ Division of Orthopaedic Oncology, Shizuoka Cancer Center Hospital, Nagaizumi, Shizuoka, ${ }^{8}$ Department of Physical Therapy, Nagoya University Graduate School Medicine, Nagoya, ${ }^{9}$ Department of Orthopedic Surgery, Aichi Cancer Center, Aichi Hospital, Okazaki, ${ }^{10}$ Department of Orthopedic Surgery, Nagoya Memorial Hospital, Nagoya, Aichi, Japan
\end{abstract}

Correspondence: Tomoki Nakamura Department of Orthopaedic Surgery, Mie University Graduate School of Medicine, 2-I74, Edobashi, Tsu-City, Mie 514-8507, Japan

Email tomoki66@clin.medic.mie-u.ac.jp

\begin{abstract}
The oncological outcome after lung metastasis in patients with chondrosarcoma of the extremities has not been reported. Between June 2000 and June 2013, 179 patients with chondrosarcoma in the extremities were treated at eleven hospitals. Twenty consecutive patients (11.2\%) developed lung metastases after initial treatment of primary chondrosarcoma in the extremities. We investigated the oncological outcome of 20 chondrosarcoma patients with lung metastasis. There were 14 males and six females with a mean age of 49 years. The mean duration between primary surgery and appearance of lung metastases was 34 months. The mean follow-up period was 48 months. We excluded patients with lung metastasis at the time of presentation from this study. At the final follow-up, four of 20 patients had no evidence of disease, four were alive with disease, and twelve had died of disease. The 3- and 5-year survival rates after lung metastasis were $51.5 \%$ and $45.7 \%$, respectively. Tumor grade, extrapulmonary metastasis, and treatment for lung metastases including metastasectomy and radiofrequency ablation were identified by univariate analysis to be significant prognostic factors for oncological analysis. In conclusion, this study evaluated the oncological outcome in patients with chondrosarcoma of the extremities with lung metastasis. Although a large-scale study might be required to confirm the results of this study, we suggest that metastasectomy and/or radiofrequency ablation should be considered to improve postmetastatic survival.
\end{abstract}

Keywords: chondrosarcoma, lung metastasis, radiofrequency ablation, metastasectomy, extremity

\section{Introduction}

Chondrosarcoma is the second most frequently observed primary sarcoma of bone. ${ }^{1}$ Surgical resection remains the mainstay of treatment owing to the limited effects of radiation therapy and chemotherapy. ${ }^{1-3}$ While the 5 -year survival rate of patients with grade 1 tumors was $90 \%$, only $40 \%-60 \%$ of patients with grades 2 and 3 tumors could survive after 5 years. ${ }^{4}$ Mesenchymal chondrosarcoma is rare but has a relatively better prognosis, with $80 \%$ survival rate at 5 years, if the primary tumor is localized. ${ }^{5}$ Dedifferentiated chondrosarcoma is a rare, particularly aggressive subtype of chondrosarcoma and is associated with an even poorer prognosis, with a $20 \%-30 \%$ survival rate at 5 years. ${ }^{4,6}$ Patients with pelvic chondrosarcoma were often reported to have poor prognoses because the surgical treatment of a pelvic lesion is challenging and a chondrosarcoma at the pelvic lesion has a high potential for metastasis. ${ }^{78}$ However, it is considered that metastasis is less common in patients with chondrosarcoma of extremities. ${ }^{1,2,9}$ Therefore, there are no reports on oncological outcome after lung metastasis in patients 
with chondrosarcoma of the extremities. In this study, we investigated the oncological outcome in 20 chondrosarcoma patients with lung metastasis at the institutions under the Tokai Musculoskeletal Oncology Consortium.

\section{Patients and methods}

Tokai Musculoskeletal Oncology Consortium was formed in 2014 to improve the care of patients with musculoskeletal tumors and to improve the knowledge in all aspects of the biology of these tumors, including basic and clinical research. All the physicians of this consortium consisting of eleven hospitals are specialized in orthopedic oncology.

Between June 2000 and June 2013, 179 patients with chondrosarcoma in the extremities were treated at eleven hospitals. Twenty consecutive patients (11.2\%) developed lung metastases after the initial treatment of primary chondrosarcoma of the extremities. We excluded patients with lung metastasis at the time of presentation from this study. There were 14 males and six females with a mean age of 49 years (range, 27-81 years). The details on the number and diameter of lung metastases are summarized in Table 1. The distribution of chondrosarcoma subtype was as follows: conventional chondrosarcoma $(n=14$; grade 2 in eleven patients and grade 3 in three patients), dedifferentiated chondrosarcoma $(n=5)$, and mesenchymal chondrosarcoma $(n=1)$. Local recurrence occurred in six patients. Two patients developed local recurrence after the diagnosis of lung metastasis. Six patients developed extrapulmonary metastasis at the diagnosis of lung metastasis (pelvis, $n=2$; pleural, $n=1$; lymph node, $n=1$; soft tissue, $n=1$; vertebrae, $n=1$ ). The mean follow-up period was 48 months.

The primary purpose of this study was to elucidate the prognostic factors associated with patient survival after first lung metastasis using univariate and multivariate analyses. The variables included nine characteristics. Age and sex were selected to represent individual clinical covariates. Tumor grade and development of local recurrence were selected for the assessment of primary sarcoma lesions. The maximum metastatic tumor size and number of metastasis at the time of initial diagnosis, extrapulmonary metastasis, chemotherapy, and surgical treatment were also chosen as variables. We defined that the treatment for lung metastases included metastasectomy and radiofrequency ablation (RFA).

The resectability of the lung metastases and indications for RFA were judged by a multidisciplinary team consisting of orthopedic surgeons, thoracic surgeons, and interventional radiologists after considering the number of tumors, location, the patient's lung function, comorbidities, and patient's prognosis.
Table I Patient characteristics

\begin{tabular}{|c|c|}
\hline Variables & \\
\hline \multicolumn{2}{|l|}{ Age (years) } \\
\hline Mean & 49 \\
\hline Range & $27-81$ \\
\hline \multicolumn{2}{|l|}{$\operatorname{Sex}(n)$} \\
\hline Male & 14 \\
\hline Female & 6 \\
\hline \multicolumn{2}{|l|}{ Primary site } \\
\hline Femur & 7 \\
\hline Tibia & 5 \\
\hline Humerus & 4 \\
\hline Scapula & 3 \\
\hline Fibula & I \\
\hline \multicolumn{2}{|c|}{ No of lung metastasis } \\
\hline Single & 7 \\
\hline Multiple & 13 \\
\hline \multicolumn{2}{|c|}{ Size of lung metastasis $(\mathrm{mm})$} \\
\hline Range & $2-45$ \\
\hline \multicolumn{2}{|c|}{ Tumor grade } \\
\hline G2 & II \\
\hline G3 & 4 \\
\hline Dedif & 5 \\
\hline \multicolumn{2}{|c|}{ Local recurrence before metastasis ( $n$ ) } \\
\hline Yes & 4 \\
\hline No & 16 \\
\hline \multicolumn{2}{|c|}{ Extrapulmonary metastasis $(n)$} \\
\hline Yes & 6 \\
\hline No & 14 \\
\hline \multicolumn{2}{|c|}{$\begin{array}{l}\text { Duration between primary surgery and appearance of lung } \\
\text { metastases (months) }\end{array}$} \\
\hline Mean & 34 \\
\hline Median & 25 \\
\hline Range & $1-89$ \\
\hline
\end{tabular}

Abbreviation: Dedif, dedifferentiated.

The statistical association of the clinicopathological factors was evaluated using Mann-Whitney $U$-test for quantitative data and Fisher's exact test or $\chi^{2}$ test for qualitative data. Overall survival was defined as the time from initial diagnosis of lung metastasis to the date of death or last follow-up. Survival curves were constructed using the Kaplan-Meier method. The log-rank test was used to compare the disease-specific survival of the patients. A value of $P<0.05$ was considered to be significant in all statistical analyses. The statistical software package Stat View Version 5.0 (SAS Institute, Cary, NC, USA) was employed for analysis. This study was approved by the Mie University Hospital review board, and written informed consent was obtained from all patients.

\section{Results}

Nine of 20 sarcoma patients underwent metastasectomy $(n=8)$ or RFA ( $n=1)$ for the initial lung metastasis (Table 2). There was a significant difference in the number of metastases in the patients who underwent metastasectomy or RFA and 
Table 2 Comparison between patients with or without surgical treatment for all 20 patients

\begin{tabular}{|c|c|c|c|}
\hline Variables & $\begin{array}{l}\text { Patients } \\
\text { with surgical } \\
\text { treatment }^{\mathbf{a}} \\
\end{array}$ & $\begin{array}{l}\text { Patients } \\
\text { without surgical } \\
\text { treatment }\end{array}$ & $P$-value \\
\hline Number (n) & 9 & 11 & - \\
\hline Mean age (years) & 48 & 51 & 0.79 \\
\hline \multicolumn{4}{|l|}{ Sex } \\
\hline Male & 7 & 7 & 0.64 \\
\hline Female & 2 & 4 & \\
\hline $\begin{array}{l}\text { Mean size of } \\
\text { metastasis }(\mathrm{mm})\end{array}$ & 13 & 19 & 0.18 \\
\hline $\begin{array}{l}\text { Mean number of } \\
\text { metastasis }\end{array}$ & 2 & 9 & 0.01 \\
\hline \multicolumn{4}{|c|}{ Initial surgical treatment } \\
\hline Wedge resection & 7 & - & - \\
\hline Lobectomy & I & - & - \\
\hline RFA & I & - & - \\
\hline
\end{tabular}

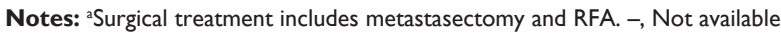
Abbreviation: RFA, radiofrequency ablation.

those who did not (Mann-Whitney $U$-test, $P=0.01$ ). In the patients with initial metastasis, the number of tumors treated varied from one to four. Complete resection was achieved in all nine patients. Seven of nine patients developed second relapse. One patient underwent metastasectomy and three patients underwent RFA. One patient was followed without treatment due to small size of relapsed metastasis. The remaining two patients had best supportive care because of difficulty with radical treatment. Chemotherapy for lung metastasis was administered in six of 20 patients. In five patients, adriamycin and ifosfamide were administered. Partial response occurred in one patient, stable disease in two, and progressive disease in one. One patient received chemotherapy as adjuvant therapy after metastasectomy. In one patient, combination therapy with adriamycin, cisplatin, and ifosfamide was administered; however, progressive disease occurred. Seven patients received no surgical treatment and chemotherapy because of their advanced disease. We examined the factors that indicated surgical treatment. The presence of extrapulmonary metastasis was a significant negative indicator for surgical treatment (Fisher's exact test, $P=0.01$ ). The six patients with extrapulmonary metastasis received no surgical treatment, while nine of 14 patients without extrapulmonary metastasis underwent surgical treatment. The size of lung metastasis and age did not affect the decision for surgical treatment (Table 3).

Regarding the oncological results at the final follow-up, four of 20 patients had no evidence of disease, four were alive with disease, and twelve had died of disease. The 3-year, 5 -year, and 10-year survival rates after lung metastasis were $51.5 \%, 45.7 \%$, and $31.4 \%$, respectively.
Table 3 Comparison between patients with or without surgical treatment in 14 patients who developed lung metastasis alone

\begin{tabular}{|c|c|c|c|}
\hline Variables & $\begin{array}{l}\text { Patients } \\
\text { with surgical } \\
\text { treatment }^{\text {a }}\end{array}$ & $\begin{array}{l}\text { Patients } \\
\text { without surgical } \\
\text { treatment }\end{array}$ & $P$-value \\
\hline Number (n) & 9 & 5 & - \\
\hline Mean age (years) & 48 & 38 & 0.29 \\
\hline \multicolumn{4}{|l|}{ Sex } \\
\hline Male & 7 & 1 & 0.99 \\
\hline Female & 2 & 4 & \\
\hline $\begin{array}{l}\text { Mean size of } \\
\text { metastasis }(\mathrm{mm})\end{array}$ & 13 & 23 & 0.09 \\
\hline $\begin{array}{l}\text { Mean number of } \\
\text { metastasis }\end{array}$ & 2 & 7 & 0.01 \\
\hline $\begin{array}{l}\text { Median survival } \\
\text { time (months) }\end{array}$ & Not reached & 9.5 & 0.01 \\
\hline \multicolumn{4}{|c|}{ Initial surgical treatment } \\
\hline Wedge resection & 7 & - & - \\
\hline Lobectomy & 1 & - & - \\
\hline RFA & 1 & - & - \\
\hline
\end{tabular}

Notes: aSurgical treatment includes metastasectomy and RFA. -, Not available. Abbreviation: RFA, radiofrequency ablation.

Tumor grade, extrapulmonary metastasis, and the treatment for lung metastases, which included metastasectomy and RFA, were significant prognostic factors in the univariate analysis (Figure 1; Table 4). We also examined survival after lung metastasis in 14 patients who did not develop extrapulmonary metastasis. The treatment for lung metastases was also a significant prognostic factor (log-rank test, $P=0.002$ ). The 3-year and 5-year disease-specific survival estimates for those who underwent metastasectomy and/or RFA were $88.9 \%$ and $77.8 \%$, respectively, and the estimates for those who did not undergo were $12.6 \%$ and $12.6 \%$, respectively. There was a significant difference in the number of metastases in the patients who underwent metastasectomy

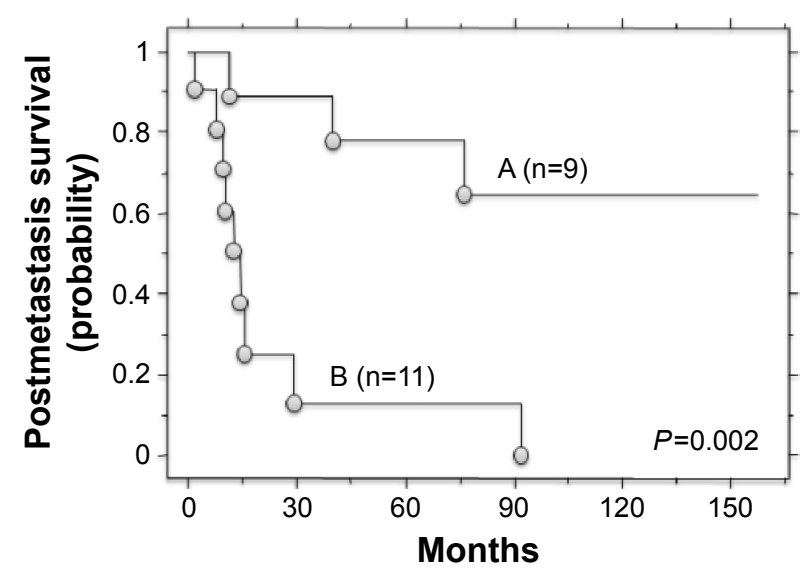

Figure I Kaplan-Meier curve showing overall survival in 20 patients. Notes: A, Patients treated with metastasectomy and/or RFA. B, Patients who were not treated.

Abbreviation: RFA, radiofrequency ablation. 
Table 4 Relationship between variables and overall survival in 20 patients with lung metastasis

\begin{tabular}{|c|c|c|c|}
\hline Variables & $\mathbf{n}$ & $\begin{array}{l}\text { 3-year } \\
\text { survival (\%) }\end{array}$ & $P$-value \\
\hline Age (years) & & & 0.14 \\
\hline$\geq 50$ & 11 & 44.4 & \\
\hline$<50$ & 9 & 60 & \\
\hline Sex & & & 0.2 \\
\hline Male & 14 & 60.6 & \\
\hline Female & 6 & 33.3 & \\
\hline No of metastasis & & & 0.48 \\
\hline Single & 8 & 75 & \\
\hline Multiple & 12 & 33 & \\
\hline Size of metastasis $(\mathrm{cm})$ & & & 0.13 \\
\hline$\geq 1.5$ & 10 & 36 & \\
\hline$<1.5$ & 10 & 67.5 & \\
\hline Tumor grade & & & 0.03 \\
\hline $\mathrm{G} 2$ & $\mathrm{II}$ & 71.6 & \\
\hline G3 or dedif & 9 & 25.4 & \\
\hline Local recurrence & & & 0.53 \\
\hline Yes & 4 & 25 & \\
\hline No & 16 & 51.6 & \\
\hline Extrapulmonary metastasis & & & 0.04 \\
\hline Yes & 6 & 16.7 & \\
\hline No & 14 & 69.2 & \\
\hline Surgical treatment $\mathrm{t}^{\mathrm{a}}$ & & & 0.002 \\
\hline Yes & 9 & 88.9 & \\
\hline No & 11 & 12.6 & \\
\hline Relapse-free period (years) & & & 0.26 \\
\hline$\geq 2$ & 11 & 60 & \\
\hline$<2$ & 9 & 41.7 & \\
\hline
\end{tabular}

Note: aSurgical treatment includes metastasectomy and RFA.

Abbreviations: dedif, dedifferentiated; G, grade; RFA, radiofrequency ablation.

and/or RFA and those who did not undergo (Mann-Whitney $U$-test, $P=0.01)$. The size of lung metastasis and age did not affect the decision of surgical treatment (Table 3).

\section{Discussion}

Approximately $22 \%-32 \%$ of patients with chondrosarcoma develop metastasis. ${ }^{1,2,9}$ The rate of metastasis is related to histological tumor grade. ${ }^{1-4,9}$ Moreover, patients with large tumors, pelvic lesions, high-grade tumors, and local recurrence have been reported to be at high risk for metastasis and poor survival. ${ }^{1-4,9}$ Patients with chondrosarcoma of the extremities have shown superior survival and low incidence of metastasis because it is potentially considered to have a lower histological tumor grade and adequate surgical margin, compared to pelvic lesions. Probably due to the rarity of metastasis, there are no reports on survival and prognostic factors for survival after lung metastasis in patients with chondrosarcomas of the extremities. In the 13-year study period, 20 of 179 patients with chondrosarcoma of the extremities who were treated at our hospitals developed lung metastasis.
Therefore, the lung metastasis in chondrosarcoma patients with extremity may be relatively rare in comparison to the incidence in patients with pelvic chondrosarcoma. In this study, treatment for lung metastasis, which included metastasectomy and RFA, extrapulmonary metastasis, and tumor grade were prognostic factors for survival after lung metastasis in univariate analysis; however, a multivariate analysis was not performed due to the small number of patients. Furthermore, we also examined the survival in 14 patients who developed pulmonary metastasis alone and found that treatment for lung metastases, which included metastasectomy and RFA, was also a significant prognostic factor. The number of lung metastases affected the decision to perform metastasectomy and/or RFA. The 3-year and 5-year survival rates after lung metastasis were $51.5 \%$ and $45.7 \%$, respectively. This result is better than that for osteosarcoma patients. ${ }^{10}$ Although it may be partially because our cases included eleven patients with grade 2 tumor, metastasectomy and/or RFA would be considered to improve postmetastatic survival for selected patients.

The presence of extrapulmonary metastasis was a significant negative indicator for surgical treatment, and postmetastatic survival was identified as a significant prognostic factor by univariate analysis. To date, the presence of extrapulmonary metastasis as a prognostic factor in chondrosarcoma patients with lung metastasis was not investigated. Furthermore, this topic remains to be studied in patients with osteosarcoma and soft tissue sarcoma. ${ }^{11,12}$ Our results possibly suggested that the indicators for the treatment of lung metastasis should be carefully determined if extrapulmonary sites are uncontrolled. However, if the extrapulmonary sites can be controlled, we believe surgical treatment should be considered.

Recently, RFA has been accepted as a relatively safe and useful therapeutic option for the treatment of unresectable non-small-cell lung cancer and lung metastases. ${ }^{13-17}$ It has been demonstrated that RFA does not significantly decrease the lung function parameters and is therefore repeatable. ${ }^{18}$ The local control rate after RFA in patients with sarcoma is reported to be $89.6 \%-95 \%,{ }^{16,19,20}$ however, Lanuti et al ${ }^{21}$ reported that RFA is associated with increased rates of local failure in tumors $\geq 3 \mathrm{~cm}$ and in contact with larger segmental vessels. Therefore, we recommend that patients with lung metastasis should be examined by a multidisciplinary team that includes thoracic surgeons, interventional radiologists, and orthopedic oncologists so that the most appropriate treatment approach can be identified for each patient.

There were some limitations in our study. The small sample size is a study limitation. The retrospective study 
is another study limitation. The positive results achieved in patients who underwent metastasectomy and/or RFA might be influenced by selection bias because patients who underwent metastasectomy and/or RFA have better lung conditions or more indolent tumors, compared to those who did not undergo.

\section{Conclusion}

This study showed the oncological outcome in patients with chondrosarcoma of the extremities with lung metastasis. Although a large-scale study might be required to confirm these results, metastasectomy and/or RFA should be considered to improve postmetastatic survival for selected patients.

\section{Acknowledgments}

We especially thank Doctors Ishimura D (Fujita Health University Hospital), Shido Y (Hamamatsu University Hospital), Nagano A (Gifu University Hospital), and Wasa J (Sizuoka Cancer Center) for collecting the questionnaires.

\section{Disclosure}

The authors report no conflicts of interest in this work.

\section{References}

1. Lee FY, Mankin HJ, Fondren G, et al. Chondrosarcoma of bone: an assessment of outcome. J Bone Joint Surg Am. 1999;81(3):326-338.

2. Gitelis S, Bertoni F, Picci P, Campanacci M. Chondrosarcoma of bone: the experience at the Istituto Orthopedico Rizzoli. J Bone Joint Surg. 1981;63(8):1248-1257.

3. Fiorenza F, Abudu A, Grimer RJ, et al. Risk factors for survival and local control in chondrosarcoma of bone. J Bone Joint Surg Br. 2002;84(1): 93-99.

4. Rizzo M, Ghert MA, Harrelson JM, Scully SP. Chondrosarcoma of bone. Analysis of 108 cases and evaluation for predictors of outcome. Clin Orthop Relat Res. 2000;(391):224-233.

5. Frezza AM, Cesari M, Baumhoer D, et al. Mesenchymal chondrosarcoma: prognostic factors and outcome in 113 patients. A European Musculoskeletal Oncology Society study. Eur J Cancer. 2015;51(3):374-381.

6. Grimer RJ, Gosheger G, Taminiau A, et al. Dedifferentiated chondrosarcoma: prognostic factors and outcome from a European group. Eur J Cancer. 2007;43(14):2060-2065.
7. Pring ME, Weber KL, Unni KK, Sim FH. Chondrosarcoma of the pelvis. A review of sixty-four cases. J Bone Joint Surg Am. 2001;83-A(11): 1630-1642.

8. Sheth DS, Yasko AW, Johnson ME, Ayala AG, Murray JA, Romsdahl MM. Chondrosarcoma of the pelvis. Prognostic factors for 67 patients treated with definitive surgery. Cancer. 1996;78(4):745-750.

9. Andreou D, Ruppin S, Fehlberg S, Pink D, Werner M, Tunn PU. Survival and prognostic factors in chondrosarcoma. Results in 115 patients with long-term follow-up. Acta Orthop. 2011;82(6):749-755.

10. Leary S, Wozniak AW, Billup CA, et al. Survival of pediatric patients after relapsed osteosarcoma: the St. Jude Children's Research Hospital experience. Cancer. 2013;119(14):2645-2653.

11. Predina JD, Puc MM, Bergey MR, et al. Improved survival after pulmonary metastasectomy for soft tissue sarcoma. J Thorac Oncol. 2011; 6(5):913-919.

12. Okiror L, Peleki A, Moffat D, et al. Survival following pulmonary metastasectomy for sarcoma. Thorac Cardiovasc Surg. 2016;64(2): 146-149.

13. Dupuy DE, Zagoria RJ, Akerley W, Mayo-Smith WW, Kavanagh PV, Safran H. Percutaneous radiofrequency ablation of malignancies in the lung. AJR Am J Roentgenol. 2000;174(1):57-59.

14. Suh RD, Wallace AB, Sheehan RE, Heinze SB, Goldin JG. Unresectable pulmonary malignancies: CT guided percutaneous radiofrequency ablation-preliminary results. Radiology. 2003;229(3):821-829.

15. Akeboshi M, Yamakado K, Nakatsuka A, et al. Percutaneous radiofrequency ablation of lung neoplasms: initial therapeutic response. J Vasc Interv Radiol. 2004;15(5):463-470.

16. Nakamura T, Matsumine A, Yamakado K, et al. Lung radiofrequency ablation in patients with pulmonary metastases from musculoskeletal sarcomas. Cancer. 2009;115(16):3774-3781.

17. Ding JH, Chua TC, Glenn D, Morris DL. Feasibility of ablation as an alternative to surgical metastasectomy in patients with unresectable sarcoma pulmonary metastases. Interact Cardiovasc Thorac Surg. 2009;9(6): 1051-1053.

18. de Baère T, Palussière $\mathrm{J}$, Aupérin A, et al. Midterm local efficacy and survival after radiofrequency ablation of lung tumors with minimum follow-up of 1 year: prospective evaluation. Radiology. 2006;240(2): 587-596.

19. Palussiere J, Italiano A, Descat E, et al. Sarcoma lung metastases treated with percutaneous radiofrequency ablation: results from 29 patients. Ann Surg Oncol. 2011;18(13):3771-3777.

20. Koelblinger C, Strauss S, Gillams A. Outcome after radiofrequency ablation of sarcoma lung metastases. Cardiovasc Intervent Radiol. 2014;37(1): 147-153.

21. Lanuti M, Sharma A, Willers H, Digumarthy SR, Mathisen DJ, Shepard JA. Radiofrequency ablation for stage I non-small cell lung cancer: management of locoregional recurrence. Ann Thorac Surg. 2012;93(3): 921-927.
OncoTargets and Therapy

\section{Publish your work in this journal}

OncoTargets and Therapy is an international, peer-reviewed, open access journal focusing on the pathological basis of all cancers, potential targets for therapy and treatment protocols employed to improve the management of cancer patients. The journal also focuses on the impact of management programs and new therapeutic agents and protocols on

\section{Dovepress}

patient perspectives such as quality of life, adherence and satisfaction. The manuscript management system is completely online and includes a very quick and fair peer-review system, which is all easy to use. Visit http://www.dovepress.com/testimonials.php to read real quotes from published authors. 